\title{
ĐĂC ĐIỂM LÂM SÀNG VÀ HİNH ẢNH SIÊU ÂM QUA ĐƯỜNG ÂM ĐẠO CHỬA NGOÀI TỬ CUNG
}

\author{
Nguyễn Văn Sang ${ }^{1,3}$, Doãn Văn Ngọc ${ }^{1,2}$, \\ Vũ Sỹ Quân ${ }^{1}$, Trần Phan Ninh ${ }^{3,4}$
}

\section{TÓM TẮT}

Nghiên cứu 61 bệnh nhân CNTC được siêu âm đầu dò âm đạo trước mổ, được phẫu thuật tại khoa Phụ sản Bệnh viện $E$ trong thời gian từ tháng 7 năm 2019 đến tháng 10 năm 2020. Kết quả: Tuổi hay gặp từ 30 đến 39 , trung bình $34 \pm 7,14.55,7 \%$ có tiền sử nao hút thai, $24,6 \%$ có tiền sử đã từng CNTC. Khi vào viện $11,5 \%$ bênh nhân có choáng, đau bung $96,7 \%$, chầm kinh $77,0 \%$ và ra máu âm đạo 60,6\%. Khám lâm sàng 63,9\% bệnh nhân di động tử cung đau, cùng đồ khám đau $50,8 \%$, phần phư có khối nề $41,0 \%$, phản ứng thành bung $31,1 \%$ và tử cung to hơn bình thường chiếm $14,7 \%$. Nồng độ $\beta$ hCG trung bình $2.235 \pm$ $4.767 \mathrm{mIU} / \mathrm{mL}$; thấp nhất: $44,9 \mathrm{mIU} / \mathrm{mL}$; cao nhất: $35.176 \mathrm{mIU} / \mathrm{mL}$. Hình ảnh túi thai không điển hình chiếm 78,7\%; điển hình 9,8\%. Kích thước khối chửa từ 20-40mm chiếm tỷ lệ cao nhất (39,3\%). Hình ảnh dịch Douglas chiếm cao nhất $73,8 \%$ phù hợp với kết quả phẫu thuật thấy máu trong ổ bụng chiếm $74,2 \%$, dịch buồng tử cung chiếm $22,9 \%$, dịch ổ bụng chiếm $60,6 \%$. Đố dày niểm mạc tử cung trung bình 8,93 \pm $4,35 \mathrm{~mm}(5-25 \mathrm{~mm})$ dày trên $8 \mathrm{~mm}$ chiếm $55,7 \%$. Giá trị chẩn đoán đúng của dấu hiệu trực tiếp, gián tiếp đều đạt $100 \%$. Kết luân: Siêu ầm đầu dò âm đạo có giá trị cao, giúp lâm sàng phát hiện sớm và xử lý kịp thời CNTC.

Tư khóa: Chửa ngoài tử cung, SA đâu dò âm đạo, SA CNTC.

\section{SUMMARY \\ CLINICALFEATURES AND TRASVAGINAL ULTRASOUND IMAGES OF ECTOPICPREGNANCY}

A study of 61 patients with ectopic pregnancy who received preoperative transvaginal ultrasound examination and operated at the Department of Obstetrics and Gynecology at Hospital E during the period from July 2019 to October 2020. Results: common age from 30 to 39, average $34 \pm 7.14$; $55,7 \%$ had a history of abortion; $24.6 \%$ had a history of having GEU. On admission, $11.5 \%$ of patients had shock, abdominal pain $96.7 \%$, delayed menstruation $77.0 \%$ and vaginal bleeding $60.6 \%$. Clinical examination $63.9 \%$ of patients has pain when moving the uterus, with pain when examination at a deadlock

\footnotetext{
${ }^{1}$ Bệnh viện $E_{1}$ Hà Nội

2 Trường Đại học Y Dược, ĐHQG Hà Nội

${ }^{3}$ Đai học Y Dược Thái Nguyên

${ }^{4}$ Bềnh viện Nhi Trung ương

Chịu trách nhiệm chính: Nguyễn Văn Sang

Email: dr.nguyensang@gmail.com

Ngày nhận bài: 8/10/2021

Ngày phản biên khoa hoc: $5 / 11 / 2021$

Ngày duyệt bài: 15/11/2021
}

$50.8 \%$, adnexa with mass $41.0 \%$, abdominal wall reaction $31.1 \%$ and $14,7 \%$ uterus bigger than normal. The average $\beta$ hCG concentration was $2.235 \pm$ $4.767 \mathrm{mIU} / \mathrm{mL}$; $\min : 44.9 \mathrm{mIU} / \mathrm{mL}$; $\max$ : $35,176 \mathrm{mIU} / \mathrm{mL}$. Atypical fetal sac image accounts for $78.7 \%$; typical $9.8 \%$. The size of the pregnancy mass from $20-40 \mathrm{~mm}$ accounted for $39.3 \%$. The image of Douglas fluid accounted for $73,8 \%$, consistent with the surgical results, showing that intra-abdominal blood accounted for $74.2 \%$, uterine fluid accounted for $22.9 \%$, and abdominal fluid accounted for $60.6 \%$. The average thickness of the endometrium is 8.93 $\pm 4.35 \mathrm{~mm}(5-25 \mathrm{~mm})$, over $8 \mathrm{~mm}$ thick accounting for $55.7 \%$. The correct diagnostic value of direct and indirect signsreached $100 \%$. Conclusion: Transvaginalultrasound has high value, helpingclinicalearlydetection and timelytreatment of ectopicpregnancy.

Keywords: GEU, transvaginalul trasoundexamination, GEUultrasound.

\section{I. ĐẶT VẤN ĐỀ}

Chửa ngoài tử cung (CNTC) lànguyên nhân gây tử vong cao nhất trong sản khoa ở 3 tháng đâu thai kỳ, ảnh hưởng đến tương lai sinh sản của bệnh nhân. Hiện nay, tại Việt Nam cũng như trên thế giới tỷ lệ CNTC vẫn đang tăng lên và trở thành một bệnh lý phổ biến, thường gặp trong cấp cứu sản khoa. Ớ nước ta, tỷ lệ CNTCchiếm 0,25-0,35\% trong thai kỳ, 2,8\% - 5,7\% ở nhóm bệnh nhân áp dụng các kỹ thuật hỗ trợ sinh sản; đặc biệt ở nhóm bệnh nhân làm thụ tinh trong ống nghiệm thì CNTC chiếm 2-11\% [1].

CNTC nếu không được chẩn đoán và xử trí kịp thời có thể dẫn đến vỡ khối chửa gây ngập máu trong ổ bụng, gây tử vong mẹ. Phươnng pháp điêu trị cở bản ở Việt Nam hiện tại vẫn là phẫu thuât, đăc biêt là các phẫu thuât cấp cứu khi có CNTC vỡ, nhiều bệnh nhân phải cắt vòi tử cung hay thậm chí là cắt tử cung hoàn toàn, từ đó làm ảnh hưởng nghiêm trọng đến khả năng sinh sản của người mẹ. Do vậy, việc chẩn đoán sớm CNTC có ý nghĩa rất lớn không những bảo toàn tính mạng người mẹ mà còn có khả năng bảo tồn vòi trứng, giữ gìn khả năng sinh sản của người phụ nữ.

Với sự tiến bộ của kỹ thuật chẩn đoán hình ảnh, đặc biệt là siêu âm đâu dò âm đạođã giúp chẩn đoán sớm CNTC từ khi khối thai còn rất nhỏ. Hiện nay, siêu âm đâuu dò âm đạo đã được sử dụng rộng rãi trong chẩn đoán CNTC. Với 
mong muốn tìm hiểu đặc điểm hình ảnh siêu âm CNTC bằng đầu dò âm đạo, chúng tôi thực hiện đề tài này với mục tiêu: mô tả đặc điểm lẩm sàng và hình ảnh siêu âm qua đường âm đạo ở cácbệnh nhân CNTC.

\section{II. ĐỐI TƯợNG VÀ PHƯƠNG PHÁP NGHIÊN CỨU \\ 2.1. Đối tượng nghiên cứu}

+ Tiêu chuẩn lưa chon bênh nhân

- Bệnh nhân có triệu chứng lâm sàng CNTC.

- Bệnh nhân được làm siêu âm đầu dò âm đạo chẩn đoán là CNTC

- Được mổ cấp cứu tại Khoa phụ sản Bệnh viện $\mathrm{E}$

- Hồ sơ bệnh án đầy đủ

+ Tiêu chuấn loại trừ

- Không đủ tiêu chuẩn lựa chọn

2.2. Phương pháp nghiên cứu

- Thiết kế nghiên cứu: mô tả cắt ngang.

- Cỡ mẫu: chọn mẫu không xác suất (mẫu thuận lợi), trong thời gian từ tháng 7/2019 đến tháng 10/2020 tai Bênh viện $E$, chúng tôi chọn được $61 \mathrm{BN}$ đủ tiểu chuẩn nghiên cứu, không có tiêu chuẩn loại trừ.

2.3. Xử lý số liệu: Bằng phần mềm SPSS 22.0

\section{KẾT QUẢ NGHIÊN CỨU}

\section{1. Đặc điểm lâm sàng}

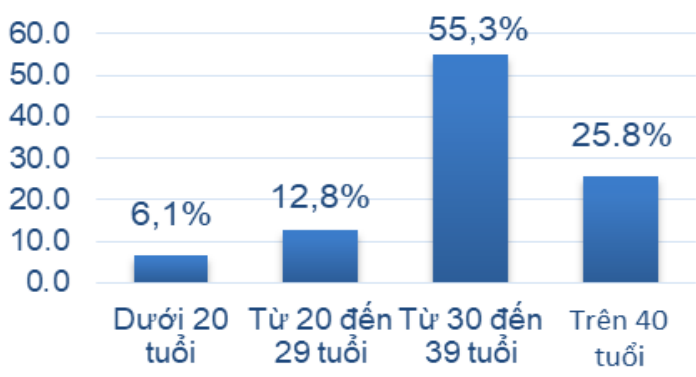

Biểu đồ 1. Phân bố theo nhóm tuổi CNTC

Nhận xét: Tuổi trung bình $34 \pm 7,14$; nhỏ nhất 19, lớn nhất 45; độ tuổi từ 30-39 chiếm $55,3 \%$.

Bảng 1. Tiền sử sản khoa

\begin{tabular}{|c|c|c|c|}
\hline \multicolumn{2}{|c|}{ Tiền sử } & $\mathbf{n}$ & $\mathbf{\%}$ \\
\hline \multicolumn{2}{|c|}{ Mố lấy thai } & 19 & 31,1 \\
\hline \multicolumn{2}{|c|}{ Chửa ngoài tứ cung $\geq 1$ lần } & 15 & 24,6 \\
\hline \multirow{2}{*}{$\begin{array}{c}\text { Nạo hút } \\
\text { thai }\end{array}$} & 1 lần & 21 & 34.4 \\
\cline { 2 - 4 } & 2 lần & 11 & 18,0 \\
\cline { 2 - 4 } & $\geq 3$ lần & 2 & 3,3 \\
\hline
\end{tabular}

Nhận xét: BN có tiền sử mố lấy thai chiếm $31,1 \%$, CNTC $24,6 \%$, nạo hút thai $55,7 \%$.

Bảng 2. Triệu chứng toàn thân và cơ năng

\begin{tabular}{|c|c|c|}
\hline Triệu chứng & $\mathbf{n}$ & $\mathbf{\%}$ \\
\hline Choáng & 7 & 11,5 \\
\hline Chậm kinh & 47 & 77,0 \\
\hline
\end{tabular}

2

\begin{tabular}{|c|c|c|}
\hline Đau bụng & 59 & 96,7 \\
\hline Ra máu âm đạo & 37 & 60,6 \\
\hline
\end{tabular}

Ghi chứ: Có thế có hơn một triệu chứng trên cùng bênh nhân.

Nhận xét: Khi vào viện $11,5 \%$ bệnh nhân có triệu chứng choáng, 96,7\% đau bụng, 77,0\% chậm kinh và $60,6 \%$ ra máu âm đạo.

Bảng 3. Triệu chứng thực thế

\begin{tabular}{|c|c|c|}
\hline Triệu chứng & $\mathbf{n}$ & $\mathbf{\%}$ \\
\hline Tử cung to hơn bình thường & 9 & 14,7 \\
\hline Phần phụ có khối nề & 25 & 41,0 \\
\hline Cùng đồ khám đau & 31 & 50,8 \\
\hline Di động tử cung đau & 39 & 63,9 \\
\hline Phản ứng thành bụng & 19 & 31,1 \\
\hline
\end{tabular}

Ghi chú: Có thế có hơn một triệu chứng trên cùng bệnh nhân.

Nhận xét: Dấu hiệu khám di động tử cung đau chiếm $63,9 \%$, cùng đồ khám đau $50,8 \%$, phản ứng thành bụng $31,1 \%$.

Bảng 4. Xét nghiệm $\beta$ hCG

\begin{tabular}{|c|c|c|}
\hline $\boldsymbol{\beta}$ hCG & $\mathbf{n}$ & $\mathbf{\%}$ \\
\hline$\leq 1000 \mathrm{mIU} / \mathrm{mL}$ & 17 & 27,9 \\
\hline 1000 đến $\leq 3000 \mathrm{mIU} / \mathrm{mL}$ & 19 & 31,1 \\
\hline 3000 đến $\leq 5000$ & 12 & 19,7 \\
\hline Trên 5000 & 13 & 21,3 \\
\hline Tống & $\mathbf{6 1}$ & $\mathbf{1 0 0}$ \\
\hline
\end{tabular}

Nhận xét: $100 \%$ bệnh nhân có nồng độ $\beta$ hCG tắng. Nồng đô $\beta$ hंCG trung bình $2.235 \pm$ $4.767 \mathrm{mIU} / \mathrm{mL}$; nhỏ nhất $44,9 \mathrm{mIU} / \mathrm{mL}$; Iớn nhất: $35.176 \mathrm{mIU} / \mathrm{mL}$ )

3.2. Đặc điểm hình ảnh siêu âm qua đường âm đao chửa ngoài tử cung

Bảng 5. Dâu hiệu trực tiếp trên siêu âm

\begin{tabular}{|c|c|c|}
\hline Dấu hiệu & $\mathbf{n}$ & $\mathbf{\%}$ \\
\hline Khối chửa điến hình & 6 & 9,8 \\
\hline Khối chửa không điến hình & 48 & 78,7 \\
\hline Không có dấu hiệu trực tiếp & 7 & 11,5 \\
\hline Tống & $\mathbf{6 1}$ & $\mathbf{1 0 0}$ \\
\hline
\end{tabular}

Nhân xét: Hình ảnh khối chửa không điển hình chiếm ưu thế $78,7 \%$; hình ảnh điển hình chỉ chiếm $9,8 \%$.

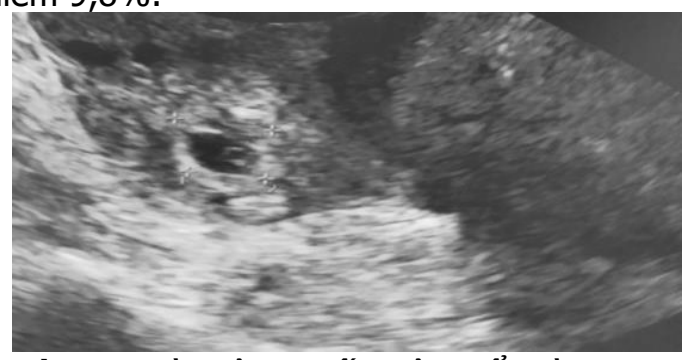

Hình 1. Hinh ảnh khôi chửa điển hinh: cạnh buồng trứng phải có túi ối kích thước $8 \times 10 \mathrm{~mm}$, túi noãn hoàng dương tính. Bệnh nhân N. T. H 39 tuổi (mã lưu trữ: 1911011537) 


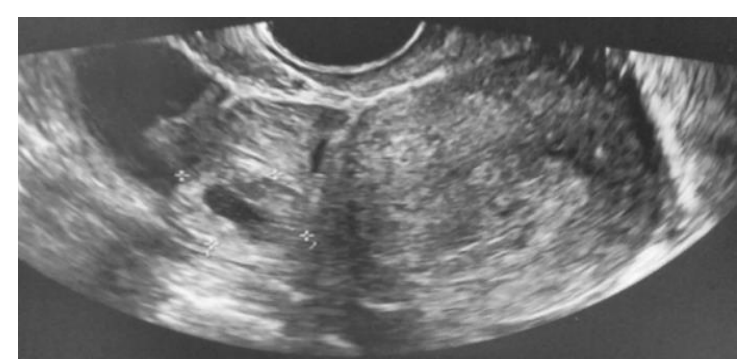

Hình 2. Hình ảnh khối chưa không điên hình: cạnh buồng trúng phải có khôi tăng âm hình nhẫn kt23×18mm. Bệnh nhân P. T. H 45 tuổi (mã lưu trữ: 18100231)

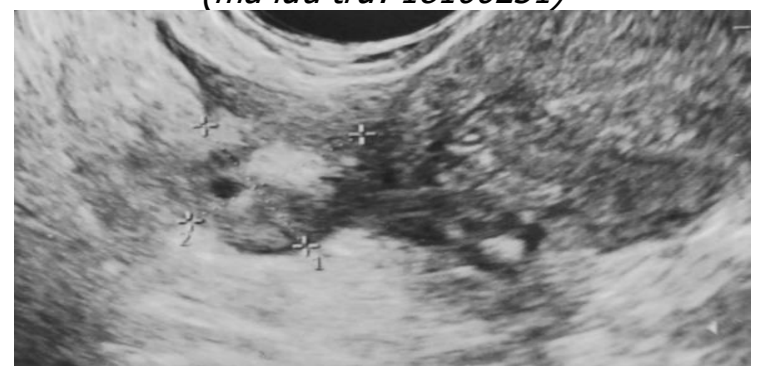

Hinh 3. Hinh ảnh khối chưa không điển hình: Cạnh trái tử cung có khôii hỗn hợp âm kích thước 17x19mm xung quanh có it dịch. Bênh nhân N.

T. T 37 tuôi (mã lưu trữ: 1912013902)

Bảng 6. Phân bố kích thước khối chửa trên siêu âm

\begin{tabular}{|c|c|c|}
\hline Kích thước khối chửa & $\mathbf{n}$ & $\mathbf{\%}$ \\
\hline$<20 \mathrm{~mm}$ & 22 & 36,1 \\
\hline $20 \mathrm{~mm} \div 40 \mathrm{~mm}$ & 24 & 39,3 \\
\hline$>40 \mathrm{~mm}$ & 15 & 24,6 \\
\hline Tống & $\mathbf{6 1}$ & $\mathbf{1 0 0}$ \\
\hline
\end{tabular}

Nhân xét: Kích thước từ 20-40mm chiếm tỷ lệ cao nhất (39,3\%), trên 40mm chiếm tỷ lệ thâp nhất (24,6\%).

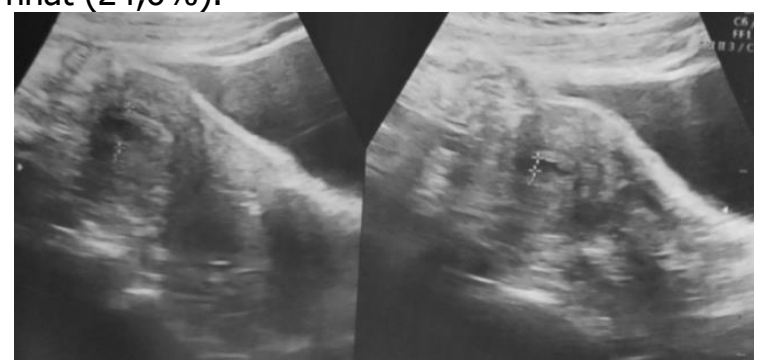

Hình 4. Hình ảnh buồng tử cung có lớp dịch dày 4mm, niêm mạc 13mm ở bệnh nhân Đ. T. K. T 43 tuôi (Mã lưu trũ 1903007917)

Bảng 7. Dâu hiệu gián tiêp

\begin{tabular}{|c|c|c|}
\hline Các dấu hiệu & $\mathbf{n}$ & $\mathbf{\%}$ \\
\hline Dịch buồng tư cung & 14 & 22,9 \\
\hline Dịch Douglas & 45 & 73,8 \\
\hline Dịch ổ bụng & 37 & 60,6 \\
\hline
\end{tabular}

Ghi chú: Có thể có hơn một dấu hiệu trên cùng bệnh nhân

Nhẩn xét: Hình ảnh dịch Douglas chiếm tỷ lệ cao nhất $73,8 \%$, dịch buồng tử cung chiếm $22,9 \%$, dịch ổ bụng chiếm 60,6\%.

Bảng 8. Độ dày niêm mạc tử cung

\begin{tabular}{|c|c|c|}
\hline Độ dày niêm mạc tử cung & $\mathbf{n}$ & $\mathbf{\%}$ \\
\hline$>8 \mathrm{~mm}$ & 34 & 55,7 \\
\hline$\leq 8 \mathrm{~mm}$ & 27 & 44,3 \\
\hline Tống & $\mathbf{6 1}$ & $\mathbf{1 0 0} \%$ \\
\hline
\end{tabular}

Nhân xét: Độ dày niêm mạc tử cung trung bình: $8,93 \pm 4,35 \mathrm{~mm}$, mỏng nhất $5 \mathrm{~mm}$, dày nhất $25 \mathrm{~mm}$, dày trên $8 \mathrm{~mm}$ chiếm $55,7 \%$.

Bảng 9. Tình trang khôi chửa trong phẫu thuât

\begin{tabular}{|c|c|c|}
\hline Tình trạng & $\mathbf{n}$ & $\mathbf{\%}$ \\
\hline Vỡ & 8 & 13,1 \\
\hline Rỉ máu & 22 & 36,1 \\
\hline Sấy qua loa & 10 & 16,4 \\
\hline Chưa vỡ & 14 & 22,9 \\
\hline Huyết tụ thành nang & 7 & 11,5 \\
\hline Tống & $\mathbf{6 1}$ & $\mathbf{1 0 0}$ \\
\hline
\end{tabular}

Nhận xét: Khối chưa rỉ máu chiếm tỷ lệ cao 36,1\%.

Bảng 10. Lượng máu trong ổ bụng khi phẫu thuật

\begin{tabular}{|c|c|c|c|}
\hline \multicolumn{2}{|c|}{$\begin{array}{c}\text { Lượng máu trong ố } \\
\text { bụng (ml) }\end{array}$} & $\mathbf{n}$ & $\%$ \\
\hline \multicolumn{2}{|c|}{ Không có máu } & 15 & 24,6 \\
\hline \multirow{2}{*}{ Có máu } & $<500$ & 38 & 62,3 \\
\cline { 2 - 4 } & $\geq 500$ & 8 & 13,1 \\
\hline \multicolumn{2}{|c|}{ Tống } & $\mathbf{6 1}$ & $\mathbf{1 0 0}$ \\
\hline
\end{tabular}

Nhận xét: Hâuu hết các trường hợp đều có máu trong ổ bụng với số lương dưới $500 \mathrm{ml}$ (62,3\%). Tỷ lệ bệnh nhân phẫu thuật có máu trong ổ bụng chiếm 74,2\%.

3.2. Giá trị của siêu âm đâu dò âm đạo trong chẩn đoán CNTC: 53 trường hợp siêu âm chẩn đoán có dấu hiêuu trực tiếp: túi thai, kết quả phẫu thuât xác nhận đúng; 8 trường hợp siêu âm chẩn đoán có dấu hiệu gián tiếp, kết quả phẫu thuật xác nhận đúng. Giá trị chẩn đoán đúng của dấu hiệu trực tiếp: $A c c=53 / 53=$ $100 \%$. Giá trị chẩn đoán đúng của dấu hiệu gián tiếp: $A c c=8 / 8=100 \%$. Giá trị chẩn đoán đúng của cả dấu hiệu trực tiếp và gián tiếp Acc = $61 / 61=100 \%$.

\section{BÀN LUẬN}

4.1. Đặc điểm lâm sàng chửa ngoài tử cung

Tuổi: Kết quả nghiên cứu của chúng tôi cho thấy tuổi hay gặp CNTC nhất từ 30 đến 39 (55,3\%),tuổi trung bình 34 土 7,14, thấp nhất 19, cao nhất 45. Theo Cao Xuân Hùng độ tuổi trung bình $30,8 \pm 5,9$ [2] thấp hơn so với kết quả nghiên cứu của chúng tôi. Khác biệt này có thể do khác nhau về số lượng và đối tượng nghiên cứu. Phụ nữ ở độ tuổi từ 30-40 thường có tiền 
sử viêm nhiễm phụ khoa, nạo hút thai... là nguyên nhân dẫn đếnCNTC. Tuy nhiên có giả thuyết cho rằng, tình trạng vòi tử cung lão hóa dẫn đến giảm nhu đông của vòi tử cung mới là nguyên nhân chính dẫn tới CNTC.

Tiền sử sản phụ khoa: Tỷ lệ mổ lấy thai ở những bệnh nhân CNTC trong nghiên cứu của chúng tôi là $31,1 \%$, cao hơn so với của Cao Xuân Hùng là $13,2 \%$ [2] và Đinh Huệ Quyên là 20,1\% [3]. Sự khác biệt này có thể do khác nhau về đía điểm và phương pháp nghiên cứu. Cho đến nay vẫn chưa có cơ chế giải thích rõ ràng về nguy cơ CNTC ở những bệnh nhân có tiền sử mổ lấy thai. Tỷ lệ bệnh nhân CNTC có tiền sử mổ lấy thai tăng có thể do chỉ định ngày càng rộng rãi và có xu hướng ngày càng tăng lên do yếu tố y học và cả yếu tố xã hội. Các trường hợp mổ lấy thai có dính ổ bụng sau mổ có thể tăng nguy cơ CNTC. Trong nghiên cứu của chúng tôi tỷ lệ bệnh nhân CNTC có tiền sử mổ CNTC chiếm 24,6\%, tỷ lệ này cao hơn so với Nguyễn Thị Bích Thanh $(13,9 \%)[4]$. Do đó khi bệnh nhân đã có tiền sử CNTC thì nguy cơ mắc CNTC sẽ tăng lên. Việc nạo phá thai gây ra viêm nhiễm vòi trứng, viêm tiểu khung, dính niêm mạc, xơ hóa ống dẫn trứng và buồng tử cung làm ảnh hưởng tới sự di chuyển và làm tổ của trứng làm tăng nguy cơ CNTC. Trong nghiên cứu này tiên sử nạo hút thai là $55,7 \%$, tỷ lệ này tương đương với nghiên cứu của Hồ Văn Việt $53,4 \%$ và cao hơn nghiên cứu của Nguyễn Thị Ngoc là 39,1\%. Sự khác biệt của các kết quả có thể là do số lượng bệnh nhân của các nghiên cứu khác nhau. Việc tuyên truyền các biện pháp tránh thai, quan hệ tình dục an toàn, tránh mang thai ngoài ý muốnlàm giảm tỷ lệ nạo hút thai - nguyên nhân dẫn đến CNTC.

Triêu chứng toàn thân: Đối với tình trạng người bệnh trước khi phẫu thuật, chúng tôi nhận thấy hầu hết bệnh nhân không có choáng $(88,5 \%)$, cao hơn kết quả của Nguyễn Thị Hồng $77 \%$, có thể trong nghiên cứu của chúng tôi bệnh nhân được phát hiện CNTC sớm và xử lý kịp thời, chưa có nhiều biến chứng do khối chửa gây ra.

Triệu chứng cơ năng: Triệu chứng cơ năng kinh điển của CNTC là chậm kinh, đau bụng, ra máu âm đạo. Đây cũng chính là các lí do thường gặp mà người bệnh đi khám. Trong nghiên cứu của chúng tôi, dấu hiệu đau bụng chiếm tỷ lệ cao nhất 96,7\% tương đương với nghiên cứu của Đinh Thị Oanh 98,6\% [5] cao hơn nghiên cứu của Cao Xuân Hùng 86,5\% [2] và Tạ Quốc Bản $56,3 \%$ [6]. Điều này có thể do tính chất đau bụng trong CNTC gặp rất đa dạng, với CNTC sớm đôi khi chỉ là đau mơ hồ hoặc không đau, lúc đầu có thể đau âm ỉ vùng hạ vị sau tăng dần khu trú về một bên hố chậu, có những trường hợp đau nhẹ nhưng cũng có thể gặp những trường hợp CNTC đển muộn bệnh nhân đau rất dữ dội, đau lan xuống hậu mồn và lan khắp ổ bụng. Chậm kinh là một dấu hiệu để chẩn đoán thai nghén và là 1 trong 3 dẩu hiệu cơ năng trong bệnh lý CNTC. Trong nghiên cứu của chúng tổi chậm kinh chiếm tỷ lệ77,0\%, thấp hơn so với nghiên cứu Đinh Thị Oanh là 98,6\%[5], cao hơn nghiên cứu của Cao Xuân Hùng 70,2\% [2]. Phần lớn các trường hợp đều có chậm kinh nhưng do CNTC được chẩn đoán ngày càng sớm, ngoài ra nhiều bệnh nhân tuy chưa đến ngày kinh nhưng lại ra máu bất thường hay nhiều phụ nữ có chu kỳ kinh không đều nên không xác định được có chậm kinh hay không. Do vậy việc phối hợp với các triệu chứng khác là điều cần thiết để chẩn đoán CNTC. Tỷ lệ bệnh nhân có ra máu âm đạo theo nghiên cứu của chứng tôi là $60,6 \%$ thấp hơn so với nghiên cứu của Hồ Văn Việt là $69,8 \%$. Trong nghiên cứu của chúng tôi tỷ lệ bệnh nhân đến viện có đầy đủ cả 3 triệu chứng cớ năng chỉ có $26,1 \%$ thấp hơn nhiều so với nghiên cứu của Nguyễn Thị Hồng là $82,4 \%$ và Hà Ngọc Đại là 86,5\% [7], như vậy để chẩn đoán CNTC có thể không chỉ dựa vào triệu chứng cơ năng. Đứng trước bệnh nhân ở độ tuổi sinh đẻ cần phải nghĩ đến CNTCđể chẩn chẩn đoán loại trừ khi có ít nhất 1 trong 3 dấu hiệu trên. Cần phải kết hợp khám thực thể và làm thêm các biện pháp cận lâm sàng khác đểnhanh chóng chẩn đoán bệnh, tránh trường hợp chẩn đoán muộn bệnh nhân có dấu hiệu nặng ảnh hưởng đến tính mang.

\section{Triệu chứng thực thể}

- Phần phụ có khối nề: trong nghiên cứu của chúng tôi khổi cạnh tử cung đau chiếm 41,0\%, tỷ lệ này thấp hơn so với nghiên cứu của Đinh Thu Hương78,6\%[8] và Đinh Huệ Quyên 74,5\% [3]. Dấu hiệu sờ thấy khối nề phần phụ là dấu hiệu có giá trị chẩn đoán cao nhất trong các triệu chứng thực thể tuy nhiên tỷ lệ này có thể khác nhau ở các tác giả. Điều này có thể giải thích do kích thước, vị trí khối chửa, lượng máu trong ổ bụng, thể trạng gầy hay béo của bệnh nhân, hay kinh nghiệm từng thây thuốc mà kết quả ở các nghiên cứu có khác nhau.

- Cùng đồ khám đau: theo nghiên cứu của chúng tôi triệu chứng này chiếm tỷ lệ $50,8 \%$ cao hơn so với nghiên cứu của Đinh Huệ Quyên $25,2 \%[3]$ và thấp hơn của Cao Xuân Hùng là $58 \%$ [2]. Sự khác nhau của các tác giả có thể do 
triệu chứng này phụ thuộc vào thời điểm thăm khám, kỹ thuật thăm khám của các bác sỹ cũng như cảm giác chủ quan và ngưỡng đau của từng bệnh nhân. Dấu hiệu cùng đồ đầy và đau là một dấu hiệu chứng tỏ có hiện tượng máu hoặc dich do rỉ máu hoặc vỡ khối chửa hoặc viêm nhiếm tiểu khung. Có tới hơn $40 \%$ bệnh nhân khám sẽ không có đấu hiệu cùng đồ đau, điều này cho thấy không có dấu hiệu cùng đồ đau cũng không thể loại trừ CNTC. Vậy nên kết hợp thêm các xét nghiệm cận lâm sàng và siêu âm là điều cần thiết.

- Phản ứng thành bụng: dấu hiệu phản ứng thành bụng chiếm tỷ lệ 31,1\% cao hơn nghiên cứu của Cao Xuân Hùng là $11,1 \%$ [2]. Sự khác nhau này có thể do trong nghiên cứu của chúng tôi cósố bệnh nhân vào viện trong tình trạng vỡ choáng nhiều hơn các nghiên cứu khác. Khi khối chửa võ lượng máu có thể chảy vào ổ bụng, các khoang gan lách làm tăng cảm ứng phúc mạc và phản ứng thành bụng. Hiện nay với sự phát triển các phương tiện cận lâm sàng nên vấn đề chẩn đoán CNTC giai đoạn sớm ở nhiều cơ sở y tế rất tốt, giảm tỷ lệ võ mất máu cho bệnh nhân. Tuy nhiên,ở một bộ phận người dân tình trạng dân trí còn kém nên tỷ lệ bệnh nhân đến bệnh viện trong tình trạng khổi chửa võ có phản ứng thành bụng vẫn còn cao, cần tích cực tuyên truyền giáo dục để nâng cao ý thức của phụ nữ trong độ tuổi sinh đẻ, đây là khuyến cáo giành cho các cơ sở trong ngành y tế.

Nông độ $\boldsymbol{\beta}$ hCG: Định lượng nồng độ $\beta$ hCG trên những trường hợp nghi ngờ có thai là cần thiết, là xét nghiệm cở bản để khẳng định có thai hay không, với độ nhạy và độ đặc hiệu rất cao, lên đến hơn $90 \%$. Nồng độ $\beta$ hCG ở người trong độ tuổi sinh đẻ không có thai là $<5 \mathrm{mIU} / \mathrm{mL}$. Trong nghiên cứu của chúng tôi, $100 \%$ trường hợp có nồng độ $\beta$ hCG trước mổ $>5 \mathrm{mIU} / \mathrm{mL}$, với trị số trung bình là $2.235 \pm 4.767 \mathrm{mIU} / \mathrm{mL}$, tương tự nghiên cứu của Phạm Thị Thanh Hiền là $1.9553 \pm 4.0188 \mathrm{mIU} / \mathrm{mL}$. Theo Vương Tiến Hòa, nếu thai làm tổ trong tử cung thì nồng độ $\beta$ hCG huyết thanh sau 48 giờ sẽ tăng $\geq 66 \%$, nếu nồng độ $\beta$ hCG huyết thanh định lượng sau $48 \mathrm{~h}$ tăng $<66 \%$ thì nghĩ đến thai ngoài tử cung. Tuy nhiên sự tăng chậm của nồng độ $\beta$ hCG không phân biệt được thai ngoài tử cung và thai trong tử cung dọa sảy.

Tỷ lệ bệnh nhân CNTC có nồng độ $\beta$ hCG $\leq$ $1000 \mathrm{mUI} / \mathrm{mL}$ chiếm $27,9 \%$ kết quả này tương đương nghiên cứu của Nguyễn Thị Ngọc là $27,4 \%$. Như vậy tỷ lệ phẩu thuật CNTC trên bệnh nhân có $\beta$ h'CG $\leq 1000$ còn cao.
4.2. Đặc điểm hình ảnh siêu âm qua đường âm đạo chửa ngoài tử cung

\subsubsection{Hình ảnh trực tiếp}

- Nghiên cứu của chúng tôi có 9,8\% hình ảnh khối chửa điển hình tương đương nghiên cứu của Võ Thành Ngọc là $8,3 \%$. Thấp hơn nghiên cứu của Nguyễn Thị Hồng là $46,5 \%$. Khác biệt này có thể do khác nhau về địa điểm nghiên cứu.

- Kích thước khối chửa: Trong nghiên cứu của chúng tôi, kích thước trung bình của khối chửa là $28,72 \pm 5,69 \mathrm{~mm}$ (nhỏ nhất $8 \mathrm{~mm}$, lớn nhất $45 \mathrm{~mm}$ ), tương tự như kết quả nghiên cứu của Vương Tiến Hòa kích thước trung bình khối phần phụ là $27 \mathrm{~mm}$. Sự phát triển của công nghệ máy siêu âm đã cho ra hình ảnh độ phân giải cao nên chẩn đoán sớm hơn, bệnh nhân đến khám sớm hơn khi có dấu hiệu thai nghén.

\subsubsection{Dấu hiệu gián tiếp}

- Dịch buồng tử cung: dịch buồng tử cung là do phản ứng chế tiết của màng rụng niêm mạc tử cung, đáp ứng với nội tiết trong thời kỳ có thai khi thai làm tổ, cũng có thể là dịch máu do vòi trứng bị rạn. Dịch buồng tử cung có thể gây nên hình ảnh túi ối giả. Trong nghiên cứu của chúng tôi có 14 bệnh nhân trên siêu âm có dịch trong buồng tử cung chiếm 22,9\%.

- Dịch Douglas: trong nghiên cứu siêu âm qua đầu dò âm đạo phát hiện 45trường hợpchiếm $73,8 \%$, cao hơn nghiên cứu của Nguyễn Thị Hồng tỷ lệ túi cùng Douglas có dịch chỉ $12,1 \%$, thấp hơn của Hà Ngọc Đại là $91,6 \%$ [7] và Phan Viết Tâm là $78,02 \%$. Kết quả của chúng tôi phù hợp với kết quả phẫu thuật thấy máu trong ổ bụng chiếm $74,2 \%$. Hình ảnh có dịch Douglas là một dấu hiệu rất có giá trị chẩn đoán CNTC, theo Trần Bá Tín khi có hình ảnh dịch túi cùng sau thì khả năng bị CNTC gấp 5 lần khả năng không có dịch túi cùng sau mà bị CNTC. Có dịch ở cùng đồ là dịch máu tăng âm do rỉ, võ khối chửa.

- Độ dày niêm mạc tử cung trên siêu âm đầu dò âm đạo: Niêm mạc tử cung dày lên do nội tiết tố thai nghén, do đó khi niêm mạc tử cung dày trên siêu âm gợi ý có thai. Trong nghiên cứu của chúng tôi đa số bênh nhân có niêm mạc tử cung dày hơn bình thường $(>8 \mathrm{~mm})$ chiếm tỷ lệ $55,7 \%$, tuy nhiên cũng có những trường hợp niêm mạc tử cung rất mỏng có thể do bệnh nhẩn đã nạo buồng tứ cung trước đó. Độ dày trung bình trong nghiên cứu của chúng tồi là $8,93 \pm$ $4,35 \mathrm{~mm}$. Tương tự nghiên cứu của Nguyễn Văn Hà là $8,413 \mathrm{~mm}$.

- Dấu hiệu không có túi thai trong buồng tử cung: Đối với thai bình thường, sẽ phát hiện được túi thai trong tử cung bằng siêu âm đường 
âm đạokhi $\beta$ hCG $\geq 1500-2000 \mathrm{mIu} / \mathrm{mL}$. Trong trường hợp $\beta$ hCG $\geq 1500-2000 \mathrm{mIU} / \mathrm{mL}$ mà không thấy túi thai trong buồng $\mathrm{TC}$, kèm theo các triệu chứng như chậm kinh, đau bụng, ra máu âm đạo cần nghĩ tới CNTC. Tuy nhiển cũng có những trường hợp vừa có thai trong $\mathrm{BTC}$ vừa có thai ngoài tử cung, đặc biệt nguy cơ cao ở nhóm phụ nữ được hố trợ sinh sản. Hiện nay tỷ lệ đa thai đang tăng lên do sự phát triển của các kỹ thuật hỗ trợ sinh sản, làm cho tỷ lệ thai trong - thai ngoài tử cung cũng tăng lên. Tần suất trước đây khoảng $1 / 30.000$ số trường hợp có thai tự nhiên và tăng hơn gần đây lên $1 / 4000$, trong nhóm có hỗ trợ sinh sản tỷ lệ này có thể lên đến $1: 100$. Vì vậy cần phải khai thác tiền sử và thăm khám kỹ chẩn đoán đúng bệnh. Trong nghiên cứu của chúng tôi không có trường hợp nào thai trong - thai ngoài tử cung. Siêu âm qua đường âm đạo được chỉ định rất rộng rãi, là phương tiện có thể sử dụng bất cứ khi nào nghi ngờ có bệnh lý, có chất lượng khảo sát vùng chậu nổi trội hởn hằn so với siêu âm qua đường bụng.

- Sử dụng đầu dò có tần số cao từ 4-9 MHz, khi áp sát các cơ quan trong vùng chậu sẽ cung cấp những hình ảnh với độ ly giải tốt hơn, cho phép nhìn thấy rõ chi tiết phần lớn các cơ quan, giúp đánh giá các tổn thương dễ dàng và chính xác hơn so với siêu âm qua đường bụng, ưu điểm này đặc biệt hữu dụng trong trường hợp bệnh nhân có thành bụng dày, nhiều mõ̃ hoặc những bệnh nhân có tử cung gập sau.

- Khám âm đạo bằng đâu dò: đầu dò đặt trong âm đạo, cùng với một tay ấn trên bụng bệnh nhân tạo một động tác thăm khám hữu hiệu để xác định độ di động của các cơ quan, đồng thời đẩy các cơ quan tới gần vị trí thuận tiện hơn để khảo sát. Ngoài ra khi khám âm đạo còn giúp xác định vị trí điểm đau, cơn đau có nguồn gốc từ một cơ quan hoặc một điểm có thể khởi phát hoăc tắng lên khi di chuyển đầu dò.

- Khác với siêu âm đường bụng, bệnh nhân không cần bàng quang đầy nước tiểu, điều này sẽ tạo sự thoải mái cho bệnh nhân cũng như bác sĩ siêu âm. Trong nghiên cứu của chúng tôi, giá trị chẩn đoán đúng của cả dấu hiệu trực tiếp và gián tiếp là $100 \%$, như vậy siêu ẩm đầu dò âm đạo là phương tiện có vai trò quan trọng trong chẩn đoán CNTC

\section{KẾT LUÂN}

- Đặc điểm lâm sàng CNTC: Tuổi hay gặp từ 30 đến 39 , trung bình $34 \pm 7,14.55,7 \%$ có tiền sử nạo hút thai,24,6\% có tiền sử đã từng CNTC.Khi vào viện $11,5 \%$ bệnh nhân có choáng, đau bụng $96,7 \%$, chậm kinh $77,0 \%$ và ra máu âm đạo $60,6 \%$. Khám lâm sàng63, $9 \%$ bệnh nhân di động tử cung đau, cùng đồ khám đau $50,8 \%$, phần phụ có khối nề $41,0 \%$, phản ứng thành bụng $31,1 \%$ và tử cung to hơn bình thường chiếm $14,7 \%$. Nồng độ $\beta$ hCG trung bình $2.235 \pm 4.767 \mathrm{mIU} / \mathrm{mL}$; thấp nhất: $44,9 \mathrm{mIU} / \mathrm{mL}$; cao nhất: $35.176 \mathrm{mIU} / \mathrm{mL}$.

- Đặc điểm hình ảnh siêu âm đâu dò âm đạo CNTC: Hình ảnh túi thai không điển hình chiếm 78,7\%; điển hình 9,8\%. Kích thước khối chửa từ 20-40mm chiếm tỷ lệ cao nhất $(39,3 \%)$, trên $40 \mathrm{~mm}$ chiếm tỷ lệ thấp nhất $(24,6 \%)$. Trong các dấu hiệu gián tiếp, hình ảnh dịch Douglas chiếm cao nhất 73,8\% phù hợp với kết quả phẫu thuật thấy máu trong ổ bụng chiếm $74,2 \%$, dịch buồng tử cung chiếm $22,9 \%$, dịch ổ bụng chiếm $60,6 \%$. Độ dày niêm mạc tử cung trung bình $8,93 \pm 4,35 \mathrm{~mm}(5-25 \mathrm{~mm})$ dày trên $8 \mathrm{~mm}$ chiếm $55,7 \%$. Giá trị chẩn đoán đúng của dấu hiệu trực tiếp, gián tiếp đều đạt $100 \%$.

\section{TÀI LIỆU THAM KHẢO}

1. Nguyen Duy Anh, "Ectopic pregnancy", Textbook of Obstetrics and Gynecology Volume 1, Vietnam National University press, Hanoi, (2016) pp. 172179 (in Vietnamese).

2. Cao Xuan Hung, "Research on ectopic pregnancy surgery at Huu Nghi Nghe An General Hospital", Hanoi Medical University (2019) (in Vietnamese).

3. Đinh Hue Quyen, "Comments on clinical, subclinical and management of ectopic pregnancy operated at the National Hospital of Obstetrics and Gynecology from January 2014 to June 2014", Hanoi Medical University (2015) (in Vietnamese).

4. Nguyen Thi Bich Thanh, "Diagnosis and treatment of ectopic pregnancy at the National Hospital of Obstetrics and Gynecology in 2006", Hanoi Medical University, (2006) (in Vietnamese).

5. Đinh Thi Oanh, "Review of diagnosis and treatment of ectopic pregnancy by laparoscopic surgery at Thai Binh Obstetrics and Gynecology Hospital in 2013", Hanoi Medical University, (2015) (in Vietnamese).

6. Ta Quoc Ban, "Comment on clinical, paraclinical characteristics and treatment methods for ectopic pregnancy at Thai Nguyen Central General Hospital and Hospital of Thai Nguyen Medical University", Mountainous Medicine and Pharmacy Newsletter, School Thai Nguyen Medical University, 1 (3), (2016) (in Vietnamese).

7. Ha Ngoc Đai et all, "Research on diagnosis and treatment of ectopic pregnancy at Bac Giang Obstetrics and Children's Hospital in 2015-2016", Mountainous Medicine and Pharmacy Newsletter, Thai Nguyen University of Medicine and Pharmacy, 3,(2016) pp. 19-25 (in Vietnamese).

8. Đinh Thu Huong, "Study on the results of surgical treatment of tubal pregnancy at Hai Phong Obstetrics and Gynecology Hospital", Thesis of Master of Medicine, Hanoi Medical University, (2018) (in Vietnamese). 